\title{
An Improved Automatic Cloud Condensation Nucleus Counter ${ }^{1}$
}

\author{
L. F. Radke And F. M. Turner \\ Dept. of A imospheric Sciences, University of Washington, Seattle 98195
}

29 April 1971

ABSTRACT

\begin{abstract}
The original automatic cloud condensation nucleus counter developed by Radke and Hobbs has been improved by reducing the size and weight of the instrument and increasing the sampling rate.

In comparison tests with four other counters, the improved automatic counter was found to give counts within $\pm 50 \%$ of the mean of all five counters.
\end{abstract}

\section{Introduction}

The measurement of cloud condensation nuclei (CCN) in thermal gradient diffusion cloud chambers (TGDCC) is still widely accomplished by illuminating the cloud, photographing a known volume, and visually counting the droplets. This technique is extremely time-consuming and severely restricts both the amount of data which can be reasonably analyzed and the rate at which the data can be manually obtained. These restrictions limit spatial resolution in aircraft measurements and make long-term continuous measurements at ground level difficult.

To surmount these problems a number of workers recently have automated (Laktionov, 1967; Radke and Hobbs, 1968; Langer, 1968; Ohta and Uchida, 1969) or semi-automated (Twomey and Davidson, 1970) the measurement of CCN. In this note we describe some improvements which have been made to the automatic CCN counter developed by Radke and Hobbs (1969); we also present the results of simultaneous measurements made with this instrument and several other $\mathrm{CCN}$ counters.

\section{Instrument improvements}

While the operating characteristics of the automatic $\mathrm{CCN}$ counter have been substantially modified, the principle of the measurement remains the same. In brief, an aerosol sample is quickly drawn into and then isolated in a thermal diffusion chamber. It has been shown that after a period of growth that the cloud droplets that form are nearly of uniform size. Their size as a function of time can be monitored by measuring the oscillations in the forward-scattered intensity of a laser beam directed through the cloud as predicted by $\mathrm{Mie}$ (1908). At the time of the peak of the first oscillation (drop radius $=r_{1}$ ), the light scattering coefficient $b_{s}$ of the cloud is measured with an integrating nephelometer

${ }^{1}$ Contribution No. 247, Department of Atmospheric Sciences, University of Washington.
(Charlson et al., 1967). Since the nephelometer can be unambiguously calibrated by measuring the Rayleigh scattering of certain gases, the concentration of droplets can be directly calculated from

$$
N=b_{s} /\left(K_{s} \pi r_{1}^{2}\right),
$$

where $K_{s}\left(r_{1}\right)=3.9$ for water drops.

The original instrument, which had a maximum sample rate of $\sim 1 \mathrm{~min}^{-1}$ at $1 \%$ supersaturation, was hardly portable with its $1.5 \mathrm{~m}^{3}$ and $150 \mathrm{~kg}$ bulk consuming $1 \mathrm{~kW}$ of power. The principle reason for this large size was to permit a very large, deep, thermal diffusion chamber $(30 \mathrm{~cm}$ long by $61 \mathrm{~cm}$ wide by $7.6 \mathrm{~cm}$ high) in which to grow an optically substantial cloud for the scattering measurement.

In the configuration used the nephelometer sensitivity was roughly proportional to the length and to the square of the height of the chamber. Unfortunately, the chamber height is also a major factor in determining the sample rate, since the steady-state time constant for the chamber supersaturation after sample change is proportional to the chamber height squared (Fitzgerald, 1970).

These conflicting design criteria were resolved by redesigning the nephelometer electronics using components of more recent design and lower noise characteristics, and also by using a zenon flash tube of increased power. These improvements permitted the chamber to be reduced to $30 \mathrm{~cm}$ by $30 \mathrm{~cm}$ by $1.7 \mathrm{~cm}$, while maintaining approximately the original signal-to-noise ratio.

The resulting improvements in size, weight and sampling rate are as follows: the size has been reduced from 1.5 to $0.27 \mathrm{~m}^{3}$, the weight from 150 to $45 \mathrm{~kg}$, the power requirement from 1 to $0.4 \mathrm{~kW}$ in normal operation, and the maximum sampling rate has been increased from 1 to $5 \mathrm{~min}^{-1}$ at $1 \%$ supersaturation.

The resulting instrument has proven even more robust than the original. It has been operated for nearly a month in the arctic and also in an extensive program of measurements from an aircraft without major problems. 


\section{Comparison measurements}

The Second International Workshop on Condensation and Ice Nuclei (IWCIN) at Ft. Collins, Colo., in August 1970 provided an opportunity for comparing the improved automatic $\mathrm{CCN}$ with five other $\mathrm{CCN}$ counters. Four of these counters were of the thermal diffusion type and, of these, three were of essentially similar design (Naval Research Laboratory, Cornell Aeronautical Laboratory and White Sands Laboratory). The fourth (ESSA) was a smaller semi-portable unit which employed comparatively low light levels for photography. The fifth counter, NCAR's continuous mixing-jet type unit, functioned only at higher supersaturations and will not be discussed here. A detailed discussion of each instrument and the results of the measurements will be made available through the IWCIN committee.

In comparing the instruments aerosol samples from a common homogeneous source were drawn simultaneously through each counter. The source was a very large, especially constructed bag, and the total concentration and size distribution of the distributed particulate was continuously monitored by an aerosol analyzer (Whitby and Clark, 1966). The aerosol analyzer was also used as an aid in controlling the production of artificial aerosols such as $\mathrm{NaCl}, \mathrm{AgI}$ and Teflon which were produced by various standard means, including vaporization and condensation, and mechanical disaggregation. Comparison measurements were also made on samples of natural air. In all, more than 50 samples were monitored, each for a duration of $1 \mathrm{hr}$ and measurements were made at $0.3,0.75$ and $1.0 \%$ supersaturation on each sample.

A typical set of measurements on the natural aerosol is shown in Fig. 1, and Table 1 summarizes the variances from the mean count obtained with each of the five counters compared. Our improved automatic $\mathrm{CCN}$ counter always gave counts within $\pm 50 \%$ of the mean values. The greatest variance was found at the lowest supersaturation $(0.3 \%)$. This is to be expected since the

Table 1. Average variance (per cent) of the CCN count obtained with various instruments from the mean value of five instruments based on fifteen measurements of natural aerosol.

\begin{tabular}{|c|c|c|c|}
\hline & \multicolumn{3}{|c|}{ Supersaturation $(\%)$} \\
\hline & 0.3 & 0.75 & 1.0 \\
\hline \multicolumn{4}{|l|}{ U. of Washington } \\
\hline integration) & -13 & +4 & +32 \\
\hline $\begin{array}{l}\text { Naval Research Laboratory } \\
\text { (video tape*) }\end{array}$ & +45 & +8 & +20 \\
\hline \multicolumn{4}{|l|}{ Cornell Aeronautical } \\
\hline $\begin{array}{l}\text { Laboratory (photog- } \\
\text { raphy) }\end{array}$ & +12 & 0 & -20 \\
\hline \multicolumn{4}{|l|}{ U. S. Army - White Sands } \\
\hline $\begin{array}{l}\text { Laboratory (photog- } \\
\text { raphy) }\end{array}$ & -43 & -4 & -4 \\
\hline ESSA (photography) & insufficient data & -8 & -28 \\
\hline
\end{tabular}

* R. E. Ruskin, NRI, reports that a photographic technique used in parallel with the video tape system gave results $10-15 \%$ greater.

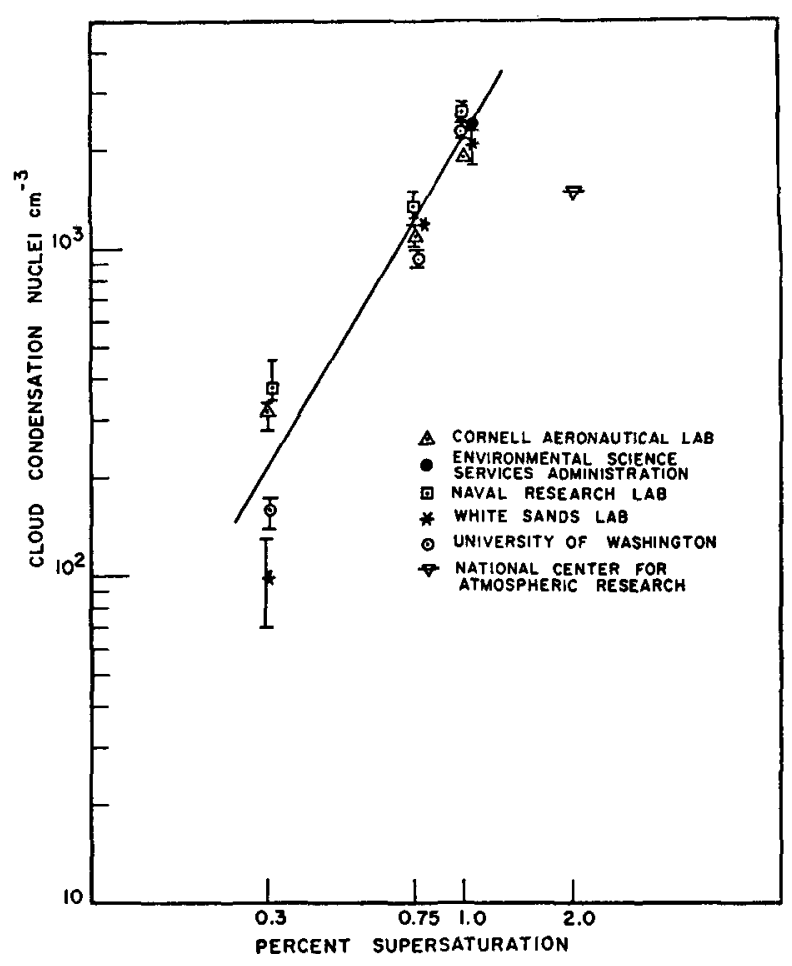

FIG. 1. Cloud condensation nucleus counts in the natural air as a function of supersaturation obtained with six different counters.

lower the supersaturation the greater is the spread in growth times in the diffusion chamber and the more sensitive it is to "haze" particles (Jiusto, 1967; Laktionov, 1968; Twomey, 1968). However, it is not clear why the spread at $0.75 \%$ supersaturation was usually less than $10 \%$, but at $1 \%$ supersaturation the spread increased again. However, various factors suggest that the major source of the differences between the five counters is probably in supersaturation control rather than in the counting techniques.

Acknowledgments. We would like to thank Prof. P. V. Hobbs for his help during the course of this work and also N. Alquist for his assistance in the electronic redesign. This research was supported by Grant GA17381 from the Atmospheric Sciences Section of the National Science Foundation and Contract 14-06-D6999 from the U. S. Department of the Interior, Bureau of Reclamation.

\section{REFERENCES}

Charlson, R. J., H. Horvath and R. F. Pueschel, 1967 : The direct measurement of atmospheric light scattering coefficient for studies of visibility and pollution. Atmos. Environ., 1, 469-478.

Fitzgerald, J. W., 1970: Non-steady-state supersaturations in thermal diffusion chambers. J. Aimos. Sci., 27, 70-72.

Jiusto, J. E., 1967: Nucleation factors in the development of clouds. $\mathrm{Ph} . \mathrm{D}$. thesis, Pennsylvania State University.

Laktionov, A. G., 1967: On the connection between the con- 
densation activity of irradiated nuclei and their size. $I_{z v}$. Atmos. Oceanic Phys., 3, 25-33.

- 1 1968: Photoelectric measurements of condensation cloud nuclei. J. Rech. Atmos., 3, 63-70.

Langer, G., 1968: Development and evaluation of a new cloud condensation nucleus counter. Proc. Intern. Conf. Cloud Physics, Toronto, 30-34.

Mie, G., 1908: Beiträge zur Optik trüber Medien, speziell kolloidaler Metallösungen. Ann. Phys., 25, 378-445.

Ohta, S., and E. Uchida, 1969: An automatic cloud nuclei counter. Proceedings Seventh International Conference on Condensation and Ice Nuclei, Prague, Academia, 268-271.
Radke, L. F., and P. V. Hobbs, 1968: An automatic cloud condensation nucleus counter. Proc. Intern. Conf. Cloud Physics, Toronto, 35-39.

$\longrightarrow$, and - 1969: An automatic cloud condensation nuclei counter. J. Appl. Meteor., 8, 105-190.

Twomey, S., 1968: Remarks on the photographic counting of cloud nuclei. $J$. Rech. Almos., 3, 85-90.

- , and K. A. Davidson, 1970: Automatic observations of cloud nucleus concentrations. $J$. Almos. Sci., 27, 1056-1059.

Whitby, K. T., and W. E. Clark, 1966: Electric aerosol particle counting and size distribution measuring system for the 0.005 to $1 \mu$ size range. Tellus $28,573-586$. 